\title{
La historia de la mujer y la historia del género en la Roma Antigua. Historiografía actual
}

\author{
María CÁndida Bengoochea Jove
}

\begin{abstract}
RESUMEN ABSTRACT
Se analizan los pasos recorridos por la denominada Historia de las mujeres desde sus comienzos hasta nuestros dias, asi como la integración de dicho modelo teórico en el estudio de la Historia antigua, en especial con respecto a la mujer romana.

An analysis will be made of the steps taken by the so-called History of Women, from its beginnings to our own days, as well as the integration of the theoretical model in the study of Ancient History, especially in what it affects the Roman woman.
\end{abstract}

\section{INTRODUCCIÓN}

El presente trabajo trata de ofrecer, por un lado, una panorámica del largo y abrupto camino iniciado por la denominada Historia de las mujeres desde sus orígenes hasta el momento actual, y por otro la incorporación de la Historia Antigua, y en concreto la historia de la mujer romana, a ese planteamiento histórico.

Partimos del hecho de que hasta los inicios del siglo xx no se planteó la necesidad de escribir una Historia de las mujeres. Representadas con insistencia en el arte, la literatura..., muy poco se sabía de ellas. En la Antigüedad su mejor $\alpha \alpha \lambda$ ós era no tenerla, que no se la nombrara; sus funciones se perpetuaban, inamovibles, de generación en generación. 
Como escribe Rousseau para la Sofía que destinó a Emilio:

"Dar placer (a los hombres), serles útiles, hacerse amar y honrar por ellos, criarlos de jovenes, cuidarlos de mayores, aconsejarlos, consolarlos, hacerles agradable y dulce la vida: he aqui los deberes de las mujeres en todos los tiempos y lo que se les ha de enseñar desde la infancia"?

Serán las revoluciones del siglo xix las que promuevan los cambios necesarios para que los nuevos sistemas educativos permitan el acceso de la mujer a la cultura, promocionando su salida de casa y su incorporación a toda una serie de trabajos, que, si en un primer momento fueron una mera prolongación de los desempeñados en el ámbito doméstico, con el tiempo ampliaron su presencia y participación en los considerados en aquellos años "sectores productivos».

Las mujeres advierten, a partir de entonces, que, cuando en la historia se habla de «nosotros», no se refieren a ellas y que cuando toman la palabra no es sino para expresar la opinión y los sentimientos de los hombres. Para acallar quizás esta evidencia los autores del siglo XIX se dedican a escribir sobre la vida cotidiana, sobre biografías de mujeres piadosas o escandalosas o sobre historia anecdótica.

Fue preciso el redescubrimiento de la familia como cédula fundamental y evolutiva de la sociedad por parte de la Antropología histórica, así como el desarrollo de la historia de las mentalidades, la reflexión política en torno a las minorías de todo tipo y condición (sexo, clase, raza, cultura...) y el impulso dado por el movimiento feminista para que se produjese el esperado cambio.

En la actualidad está amplia y comunmente admitido que las corrientes historiográficas de los últimos siglos presentan como denominador común una visión parcial de la Historia al contemplar sólo la experiencia de los hombres y mantener en secreto, es decir «silenciar», la desempeñada por las mujeres. No queremos caer en el fácil calificativo de "misoginia» y, como apunta Gonzalo Bravo, tal vez esta marginación de la mujer - sobre todo en lo concerniente a la historiografía romana- se deba a que la historia se ha basado, salvo excepciones, en hechos militares y políticos, en los que no cabría esperar un papel relevante de las mujeres ${ }^{2}$. 1991.

Citado por DuBy, G. y PerRot, M. "Introducción», en La Historia de las mujeres, Madrid

«La mujer romana y la historiografía moderna: cuestiones metodológicas y nuevas perspectivas de estudio", La mujer en el mundo antiguo, Madrid 1986, pág. 60. 
La nueva historiografía, la que coloca en el punto de mira de sus investigaciones las relaciones entre los sexos como producto de una construcción social, ha modificado los métodos y perspectivas de la historia tradicional al pasar a ser cada vez menos descriptiva, más relacional y, para muchos, más problemática.

El rechazo de unos, la crítica velada y el escepticismo de otros, no ha de frenar este proceso de rehabilitación de la mujer en la historia, pues no en vano prescindir de ella sería prescindir de la mitad de la humanidad.

\section{DE LA HISTORIA DE LAS MUJERES A LA HISTORIA $D E G E ́ N E R O$}

«Hay mujeres en la Historia y hay hombres en la Historia, y sería de esperar que ningún planteamiento histórico de un período determinado pudiera haberse escrito sin tratar de las acciones e ideas tanto de hombres como de mujeres ${ }^{3}$.

Quizás haya sido éste el propósito que inicialmente impulsó el nacimiento de la Historia de las mujeres, promovido por la segunda oleada del feminismo contemporáneo en los años sesenta, al reivindicar la presencia - y no la invisibilidad- de la mujer en el devenir histórico, no sólo como objeto de investigación sino también como agente del cambio histórico.

Hasta ese momento la historiografía académica tradicional centraba su investigación en la experiencia histórica del varón y, si abordaba la participación de la mujer, era siempre en calidad de santa, reina, reformadora o estadista.

Ni la revista Annales (publicada desde 1929) ni la historiografía marxista, a pesar de haber planteado un enfoque metodológico de «Historia total" desde la perspectiva de las clases oprimidas, se ocuparon de la problemática de la mujer, a no ser bajo perspectivas tradicionales.

¿De dónde proviene la invisibilidad de la mujer en la historia?; ¿tal vez de su nula participación en actividades políticas, sociales o culturales? ¿O más bien de un deseo manifiesto de ocultar su actividad cotidiana en el marco de la sociedad?

\footnotetext{
3 Se glosa este texto en LERNER, G., «The Challenge of Women's History», The Majority finds its Past. Placing Women in History, Nueva York 1981 (traducción española de Mary NASH en Presencia y protagonismo. Aspectos de la historia de la mujer, Barcelona 1984, pág. 10).
} 
La respuesta la encontramos en la propia concepción androcéntrica y eurocéntrica de la historia, que ha seleccionado - desde los presupuestos ideológicos de la óptica masculina-como dignos de un análisis histórico determinados acontecimientos y ha excluido otros por considerarlos de escaso interés o nula incidencia histórica.

Desde esta concepción histórica no es de extrañar que el reconocimiento explícito de la eterna sujeción femenina -planteado por Simone de Bouvoir en su libro El segundo sexo, publicado en 1949, pero apenas conocido y leído hasta 1960 - haya planteado un controvertido debate, que todavía pervive en nuestros días, entre dos teorías o tendencias:

a) la teoría de la "victimación» histórica de la mujer, promovida por una sociedad patriarcal que, partiendo de la consideración biológica inferior de la mujer, ha cuestionado su participacoión en la historia; y

b) la teoría triunfalista que, defendida por Mary Beard en su obra La mujer una fuerza en la historia y otras investigadoras como Gerda Lerner - Patricia Branca, se esfuerza en demostrar la participación activa y constante de la mujer en una amplia gama de actividades, y por ende su contribución a la historia en una medida equiparable a la del hombre ${ }^{4}$.

Así pues, en la búsqueda de sus orígenes la Historia de la mujer pasó por el estudio de mujeres notables, por la biografía y por la denominada "Historia tradicional de la Mujer», que abarcaba temas como la educación, el sufragio femenino, el control de la natalidad o la literatura femenina.

A finales de los sesenta y con el fín de ampliar los estudios de mujeres surge la "Historia Contributiva", con trabajos que versan sobre la contribución femenina a diversos movimientos, como el movimiento obrero, los movimientos nacionales, los movimientos de reforma, los de templanza, neomaltusianos y de control de natalidad...

Las críticas de algunas investigadoras actuales van en la línea de que, si bien estos trabajos son valiosos porque amplian nuestro conocimiento en este terreno, analizan únicamente la aportación femenina a tales movimientos desde la perspectiva de su efecto sobre el conjunto del movimiento y no de esa actividad sobre sí mismas y sobre las demás mujeres, reforzando de esta manera la concepción de víctima que se tiene de la mujer ${ }^{5}$.

4 Para ampliación de este debate consultar NASH, M., "Nuevas dimensiones en la historia de la mujer», Presencia y protagonismo, págs. 13ss.

5 NASH, M., op. cit., pág. 23. 
En su devenir reciente y en el afán de superación de las aportaciones historiográficas de tipo contributivo, la Historia de la mujer, al vincularse a corrientes renovadoras como la Historia social, ha logrado un gran avance al extender las áreas de investigaciónn, utilizar métodos y marcos conceptuales renovados, rechazar el modelo androcéntrico y emplazar a la mujer en el centro del análisis, obligando a los historiadores sociales a modificar los planteamientos iniciales ${ }^{6}$.

Fruto de esta nueva perspectiva son:

- Ios trabajos que desde fines de los 70 han publicado Louise Tilly, Joan Scott, Theresa McBride o Patricia Branca, quienes, alineadas en la corriente triunfalista, tratan de demostrar el protagonismo histórico de las mujeres al analizar las transformaciones de las estructuras económico-sociales, su repercusión en las interrelaciones personales y familiares, junto a conexiones con la condición laboral de la mujer;

- los estudios en torno al papel de la mujer en los movimientos sociales, como los movimientos feministas, el sufragismo, los movimientos nacionalistas, la resistencia y lucha popular, el movimiento obrero organizado...; y

- los estudios acerca del control de la natalidad, la sexualidad y la salud femeninas, como los de Renata Bridenthal, Hilda Smith, Carrol Smith-Rosenberg... ?

En un momento de gran confusión epistemológica y desde el feminismo norteamericano, a fines de los setenta surge un nuevo enfoque disciplinario, que va cobrando interés entre los historiadores e historiadoras feministas en Europa (Inglaterra, Francia, Italia y España) en los años ochenta, hasta adquirir carta de naturaleza propia en los años noventa. Nos referimos al término género.

Como decía Natalie Davis en 1975:

"Me parece que deberíamos interesarnos tanto en la historia de las mujeres como de los hombres, que no deberíamos trabajar solamente sobre el sexo oprimido, del mismo modo que el historiador de las clases sociales no puede centrarse por entero en los campesinos... ${ }^{8}$

NASH, M. op. cit., págs. 24-25.

Véase la relación de sus trabajos en NASH, M., op. cit., págs. 28-29.

8 ZEMON DAVIS, N., "Women's History in Transition: the European Case", Feminist Studies 3 (1975-1976) 90 (citado por SCOTT,J., en «El género: una categoría útil para el análisis histórico», 
Si en su acepción primigenia -y muy simple - era sinónimo de «mujeres", de "sexo", en clara alusión a la biología, cuestión que rechaza con argumentos abundantes y consistentes Gisela Bock ${ }^{9}$, en la actualidad, y dejando al margen lo puramente gramatical, el concepto género sigue conservando cierta complejidad en cuanto a su consideración.

Citaremos el significado que para algunas investigadoras actuales tiene este concepto:

1) Carmen Ramos Escandón: «género es la construcción histórico-social de la diferencia sexual» ${ }^{10}$;

2) Joan Scott: "género es un elemento constitutivo de las relaciones sociales basadas en las diferencias que distinguen los sexos y al mismo tiempo una forma primaria de relaciones significantes del poder» ${ }^{11}$;

3) Gisela Bock: "género es una categoría fundamental de la realidad socio-cultural e histórica, así como de la percepción y el estudio de dicha realidad» 12 ;

4) Gerda Lerner: "género es la definición cultural de la conducta definida como apropiada a los sexos en una sociedad dada en una época dada...una serie de roles culturales...un disfraz, una máscara, una camisa de fuerza en la que hombres y mujeres bailan su desigual danza» ${ }^{13}$; y

5) Milagros Rivera Garreta: «género es una construcción social, y lo que entendemos por hombre y mujer no son conjuntos anatómicos sino construcciones sociales y culturales con una apoyatura biológica ambigua e inestable» 14 .

Entendido así el género, como una relación socio-cultural, el campo de investigación se amplia e incluye la familia, la economia, la cultura, la religión, la sexualidad, la raza, la edad, la libertad..., y un largo etcétera.

en Historia y género. Las mujeres en la Europa moderna y contemporánea, AMELANG, J.S. y NASH, M. (eds.), Valencia 1990, pág. 24).

9 "La historia de las mujeres y la historia de género: aspectos de un debate internacional", Historia social 9 (1991) 55-57.

10 «El concepto de género y su utilidad para el análisis histórico», La Aljaba segunda época 2 (1997) 13-14.

1 ScOTT, J., op. cit, pág. 44.

12 Bock, G., op. cit., pág. 59.

13 The Creation of Patriarchy, Londres 1986, págs. 36ss, citado por Rivera, M. en Nombrar ef mundo en femenino. Pensamiento de las mujeres y teoría femenina, Barcelona 1994, pág. 172.

14 Rivera, M., op. cit., pág. 157. 
El género, concepto fundamentalmente liberador al ser formulado en los años setenta, con el paso del tiempo ha resultado menos revolucionario de lo que pareció en un momento. Gran número de artículos y libros aparecidos en los últimos años han sustituido «mujer» por «género»; ¿por qué razón?: ¿porque dicho término se ajusta más a la terminología de las ciencias sociales?; ¿porque supone una descarga de contenidos políticos, y así se desmarca de la política del feminismo?; o, como afirma Joan Scott, ¿para hacerse aceptable en el mundo académico conservador? ${ }^{15}$.

Sea el motivo que sea, se puede afirmar que una historia de las mujeres centrada en el análisis de los mecanismos de subordinación de ellas a los hombres ha facilitado el triunfo de la historia de género en los ambientes académicos, especialmente en las Universidades de los EE.UU ${ }^{16}$.

Ha contribuido igualmente a que la diversidad de mujeres que se dedican a estudios sobre la mujer haya sugerido a Stimpson la siguiente catalogación:

- a) las pioneras, que marcan el camino a seguir;

- b) las ideólogas, que intentan adaptar su feminismo a las exigencias de la profesión açadémica;

- c) las radicales, que situan su feminismo en una reivindicación teórica de transformaciones más generales en el status de la mujer;

- d) las recién llegadas, que acaban de descubrir que las mujeres son un campo académico e interesante; $y$

- e) las modernas, que se implican en el tema porque está de moda ${ }^{17}$.

En la actualidad el reto de la historia de género no es simplemente recuperar aspectos olvidados de la historia - las mujeres en la historiasino:

1. buscar las relaciones entre seres y grupos humanos, que antes habían sido omitidas;

\footnotetext{
15 ScotT, J., op. cit., págs. 27-28.

16 Rivera, M., op. cit., pág. 173.

17 BRAIDOTTI, R., "Teorías de los estudios sobre la mujer: algunas experiencias contemporáneas en Europa", Historia y fuente oral 6 (1991) 14.
} 
2. investigar cómo, cuándo y por qué se han producido las desigualdades que luego se articulan y ordenan mediante el género; y

3. estudiar la historia, no como una experiencia masculina, sino también femenina, y no desde criterios masculinos sino igualmente femeninos ${ }^{18}$.

La historia de género trataría de ofrecer, no un feminismo descarnado, un feminismo sin mujeres, ni, como señala J. Scott, un estudio de las cosas relativas a las mujeres, aunque nuevo, carente de capacidad analítica para cambiar los paradigmas históricos ${ }^{19}$, sino una historia de los sexos, que superase la simple descripción, la deconstrucción y la denuncia para llegar a las raíces del problema, esto es analizar la subordinación de las mujeres en el marco de la política sexual del patriarcado y de las formas de acabar con ella.

De esta manera se podría conciliar la historia de una mitad de la humanidad con la otra y de éstas con la historia en general, y empezar a escribir una nueva historia.

\section{LA HISTORIA DE LAS MUJERES (VERSUS HISTORIA DEL GÉNERO) EN LA ESPAÑA ACTUAL}

En España la historia de género, al considerar como objeto y sujeto de estudio a la mujer y tratar de romper con la historia tradicional, ha supuesto un cierto revulsivo, ha sido tildada de historia politizada, subversiva e ideologizada, y ha tardado en ser aceptada por la Academia.

En su evolución histórica se pueden apreciar dos etapas:

— de 1974 a 1981; y

- de 1982 en adelante ${ }^{20}$.

La primera de estas fases se ubica en el marco socio-político de los últimos años del franquismo, por lo que no es de extrañar que los primeros trabajos se centren en temas políticos, como el sufragio de la mujer o el movimiento obrero.

\footnotetext{
18 Bock G., op. cit., pág. 77.

ScotT, J., op. cit., pág. 29.

NASH, M., "Dos décadas de Historia de las mujeres en España: una consideración", Historia social 9 (1991) 137ss
} 
A este período corresponden:

- la primera Tesis de Licenciatura sobre este tema, presentada en Barcelona en 1974;

- el primer curso de Historia Social de la Mujer, organizado por el Departamento de Historia Contemporánea de la Universidad de Barcelona durante ese mismo año; y

- Seminarios (primavera de 1975) y conferencias masivas en Madrid y Barcelona.

Ligada íntimamente al desarrollo del movimiento de mujeres, la historia de las mujeres dependió de unas cuantas personas aisladas, que contaban con escasísimo apoyo y poca presencia en la Universidad. Los estudios de periodistas y escritoras, junto a memorias y escritos autobiográficos de mujeres activistas -en la línea de la Historia Contributiva y con clara tendencia a la postura "victimista»- fueron las aportaciones más importantes.

En la segunda de dichas etapas, la que va de 1982 en adelante, la consolidación de la democracia, el desarrollo de la conciencia feminista, la incorporación de nuevos países a la C.E.E. en 1986 - cuyo efecto más inmediato fue la creación del primer organismo oficial diseñado para proteger a la mujer (el Instituto de la Mujer)- - y el cada día mayor número de Profesoras Titulares en la Universidad han multiplicado el elenco de trabajos, al tiempo que se han abierto a nuevos campos y disciplinas, como la Historia del arte, la Literatura, la Musicología...

Salvo honrosas excepciones de carácter privado, como la del Centro feminista de Estudios y Documentación de Madrid, la editorial feminista La Sal en Barcelona y los cursos organizados por el Instituto de Promoción de Estudios Sociales del País Vasco, ha sido el ámbito universitario el foro fundamental de desarrollo y difusiór, y las vías utilizadas las siguientes:

1) la emprendida por el Centre d'Investigació Histórica de la Dona (CIHD), fundado en 1982 como una sección autónoma del Centre d'Estudis Historics Internacional de la Universidad de Barcelona, que desde 1987 ha introducido los primeros cursos de postgrado y masters en esta materia;

2) la de los seminarios interdisciplinares, tales como el Seminario de Estudios de la Mujer en la Universidad Autónoma de Madrid, en la Complutense de Madrid, en las Universidades del País Vasco, Valencia, Málaga y Granada, y en dos Institutos universitarios: la Fundación Ortega y 
Gasset de Madrid y el Instituto Universitario de Estudos e Desenvolvemento de Galicia en Santiago de Compostela ${ }^{21}$;

3) la utilizada en el País Vasco, donde el Seminario de la Mujer de la Universidad vasca se costea con fondos de la Diputación; y

4) la que constituye en la actualidad el Tercer Ciclo de postgrado - como los que se imparten de forma interdisciplinar en la Universidad de Oviedo desde hace unos pocos años - así como la organización de conferencias cortas y seminarios ${ }^{22}$.

Aunque, expuesto así, puede parecer que la historia de las mujeres esta legitimada y convive en un plano de igualdad a nivel académico con el estudio sobre la actividad masculina en la historia, la realidad es que todavía sigue vigente un conjunto de dificultades estructurales y cierta hostilidad en algunos sectores, así como el hecho de que la escasa representatividad de temas específicos relacionados con la mujer constituyen todavía una constante en los programas oficiales de la Universidad española.

\section{LA HISTORIA DE LAS MUJERES ROMANAS EN LA ANTIGÜEDAD}

"Las mujeres guarden silencio en las asambleas, no les está permitido hablar; en vez de esto, que se muestren sumisas, como lo dice también la ley. Si quieren alguna explicación, que les pregunten a sus maridos en casa, porque es indecoroso que las mujeres hablen en las asambleas".

San Pablo, lo. 14.34-35.

\section{IV.1. Planteamiento del tema}

Si el silencio, la invisibilidad, la marginación deliberada o no, ha caracterizado la experiencia femenina en amplias épocas de la Historia, en lo referente a la Antigüedad romana ha sido una constante hasta entrados los años setenta.

21 La publicación de las Actas de los Congresos y grupos de trabajo suscitados por estos organismos ha significado una decisiva aportación.

22 Por ejemplo, entre otros, el celebrado del 29 de junio al 3 de julio de 1998 en la U.I.M.P. de Santander con el título "La mujer protagonista de la salud". 
¿Estudiar a las mujeres romanas puede ampliar o completar nuestra visión de la evolución sufrida por las distintas sociedades a lo largo de la historia?. ¿Cuándo surgieron las primeras investigaciones?; ¿qué temas han abordado?; ¿qué fuentes se han utilizado?; ¿qué espacio ocupan estos trabajos en la historiografía actual?; ¿cuál es la perspectiva de futuro?...

Aunque la producción haya sido inferior en número a la de otras etapas - por ejemplo la contemporánea-, a pesar de que la propia Mary Nash no hace mención alguna de los trabajos realizados en España en torno a los años $80^{23}$ y a pesar de la dificultad que pueden suponer las fuentes, tanto más cuanto más nos alejamos en el tiempo, trataremos de hacer una «historia» de los estudios realizados y de contestar así a los interrogantes planteados.

Desde fines del siglo xIX y durante buena parte del $x x$ las investigaciones se refieren a "mujeres célebres», reales o de ficción, con carácter general ${ }^{24}$, cuyo interés histórico radica en su relación con varones famosos (Tanaquil, Zenobia, Julia, Agripina) ${ }^{25} \ldots$, en representar «valores femeninos» negativos o positivos a los ojos de los hombres (Lucrecia, Clodia, Marcia) ${ }^{26}$ o detentar una posición de poder o un comportamiento similar al del varón (Amazonas, Livia, Boudicca, Vestales...) ${ }^{27}$.

\footnotetext{
23 "Dos décadas de Historia de las mujeres en España...", op.cit.

24 Ver, por ejemplo, entre otros: ABвOT, W.J., Notable Women in History, Filadelfia 1913; ASSA, J., Les grandes dames romaines, Paris 1958; CALZA, G., "Some Portraits of Roman Empresses", Art and Archaeology 19 (1925) 93-99; DoNALOSON, J., Woman: Her Position and Influence in Ancient Greece and Rome and among the Early Christians, Londres 1907; DEUTSCH, M.E., "Caesar's Firts Wife", CPh 12 (1917) 93-96, y "The Woman of Caesar's Family", CJ 13 (1918) 502-514; Ferrero, G., The Women of Caesars, Nueva York 1911; Hamilton, G., "The Ladies of the Last Caesars", NortAmerican Review 151 (1890) 548-566; KING, W.C. (comp.), Woman: Her Position, Influence and Achievement throught the Civilized World, her Biography, her History from the Garden of Eden to the Twentieth Century, Springfield 1902; SERVIEZ, J.R., Lives of the Roman Empresses: the History of the Lives and Secret Intrigues of the Wives, Sisters and Mothers of the Caesars, Nueva York 1935.

25 Por ejemplo los trabajos de AlEXANDER, W.H., "The Communiqué to the Senate on Agrippina's Death", CPh 49 (1954) 94-97; AverY, W., "lulia and Lucius Vinicius", CPh 30 (1935) 170171; BACHOFEn, J.J., Die Sage von Tanaquil, en Von KIENZL, E. (ed.), Gesammelte Werke, vol.VI, Basilea 1951; BICKNELL, P.J., "Agrippina's Villa at Bauli», CR N.S. 13 (1963) 261-262; Dawson, A., "Whatever Happened to Lady Agrippina?", CJ 64 (1969) 253-267; MCDANIEL, W.B., "Bauli the Scene of the Murder of Agrippina", CQ 4 (1910) 96-102.

26 Para más detalles ver BASSANI, F., Commodo e Marcia: una concubina Augusta, Venezia 1905; DoreY, T.A., "Cicero, Clodia and the Pro Caelio", G\&R 20 Ser. 5 (1958) 175-180; MCDERMOTT, W.C., "The Sisters of P.Clodius", Phoenix 24 (1970) 39-47; MalcovatI, E., Clodia, Fulvia, Marzia, Terenzia, Roma 1944; WEIL., B., Clodia: Roms Grosse Dame und Kurtisane, Zürich 1960.

27 Como exponente de ello ver, entre otros, APPLETON, Ch., Trois Episodes de l'Histoire ancienne de Rome: Les Sabines, Lucrèce, Virginie, París 1924; AlEXANDER, Ch., "A Portrait of Livia", The Metropolitan Museum of Art Bulletin 11 (1953) 168-191; DECKMAN, A.A., "Livia Augusta", CW 19 (1925) 21-25; Esdalle, K.A., "The Aged Livia", JRS 4 (1914) 139-141; DudLEY, D.R., "The Rebellion
} 
El interés suscitado por la familia procede de la teoría defendida por Bachoffen en 1871 (Das Mutterrecht) en torno a la existencia de un matriarcado antes del desarrollo de la sociedad patriarcal y a la consideración de la familia desde un punto de vista jurídico o como una institución de la biología ${ }^{28}$.

A partir de los años sesenta encontramos igualmente trabajos de carácter general ${ }^{29}$, así como estudios de carácter parcial, sobre religión, amor, trabajo, prostitución..., carentes de una metodología de trabajo, meras paráfrasis de las fuentes usadas y que han sido calificados como trabajos menores ${ }^{30}$.

Como resultado de este tipo de análisis se ha producido una imagen dual de las mujeres antiguas, que ha pervivido hasta nuestros días:

- la mujer honorable, la matrona, portadora de todas las virtudes oficiales (domestica et lanifica), y

- la ramera o prostituta, de mayor o menor categoría.

- En definitiva: cuando se abordaba el papel de la mujer y su repercusión social siempre se hacía en función de su propia biología y por su relación con el grupo familiar (madre/esposa o prostituta), y si se trataron otros aspectos el resultado fue una simple enumeración de tareas sin incardinarlas en el marco productivo de su sociedad.

Con la publicación de la obra de Simone de Beauvoir (The First Sex) en 1970 y a partir de los años ochenta, gracias al impulso del feminismo y a

of Boudicca", History Today 10 (1960) 387-394; Gardner, P., "A New Portrait of Livia", JRS 12 (1922) 32-34; PICHON, R., «Le rôle religieux des femmes dans l'ancienne Rome», Annales du Musée Guimet 34 (1912) 77-135; ScotT, M.A., "The Rebellion of Boudicca: the Burnt Layer and the Narrative of Tacitus", Pegasus 8 (1967) 12-14.

28 Para más detalles ver, como ejemplo, Brini, G., Matrimonio e divorzio nel dirito romano, varios vols., Roma 1887/89; CaRcopino, J., Daily Life in Ancient Rome; the People and the City at the Height of the Empire, New Haveil 1940; CoRbet, P.E., The Roman Law of Marriage, Oxford 1930; GAUDEMET, J., «Le statut de la femme dans l'Empire romain», La Femme (Recueils de la Societé Jean Bodin, Bruselas) 11 (1959) 191-222; GIDE, P., Étude sur la condition privée de la femme dans le droit ancien et moderne et en particulier sur le senatus-consulte velleien, París 1885; MoRIAVD, De la simple famille paternelle en drooit romain, Milán 1910.

29 Entre otros BALDSON, J.P.V.D., Roman Women: their History and Habits, Londres 1962; BARDACHE, M., Histoire des femmes, París 1967; GRIMAL,P., Histoire mondiale de la femme /, París 1965; POMEROY, S., "Selected Bibliography on Women in Classical Antiquity", en Women in the Ancient World. The Arethusa Papers, Nueva York 1984, págs. 318ss.; y SeltmanN, C., La femme dans I'Antiquité, París 1956.

30 Remitimos, por ejemplo, a DurRY, M., «Le mariage des filles impubères de la Rome antique", REL 48 bis (1970) 17-35; FInLEY, M.I., "Tle Silent Women of Rome», Horizon 7 (1965) 56-64; Marschall, I.M., "The Position of Women", A Companion to Latin Studies, Nueva York 1963 , págs. 184-190; SCHILLING, R., «Vestales et Vierges Chrétiennes dans la Rome antique», RSR 35 (1961) 113-129; Treggiarı, S., "Libertine Ladies", Classical World 64 (1971) 196-198. 
los propios avances de la Historia Antigua al aliarse con la antropología, la historia de las mentalidades y la introducción del concepto género, se ha producido un boom, surgiendo:

a) estudios de las escuelas anglosajonas acerca de la antropología de la Antigüedad, que versan sobre la religión, la mitología y la familia ${ }^{31}$;

b) estudios generales sobre las mujeres antiguas (los Women's Studies pioneros) en EE.UU. y desde Inglaterra, Francia e Italia ${ }^{32}$;

c) todo un conjunto de artículos que versan sobre la biología de la mujer (maternidad, enfermedades), su relación con los diversos cultos y ritos religiosos, los juegos, su cuerpo, la mujer y el poder... ${ }^{33}$, publicados en revistas como Arethusa, Annales, Historia... y sometidos a discusión en coloquios, comngresos y seminarios específicos, como los celebrados en Estrasburgo, Madrid, Berkshire..., o recopilaciones en algunas publicaciones que tratan a la mujer en la Antigüedad desde ópticas distintas ${ }^{34}$.

A raiz de estos «nuevos planteamientos» la historiografía moderna no nos ofrece una imagen unívoca de la mujer romana sino tres:

1. la primera, referida a la evolución histórica, la presenta como el sujeto femenino más evolucionado de todas las sociedades antiguas, al menos a partir de la República, cuando logra un grado de emancipación económica sin precedentes, que le permite disponer libremente de «sus" bienes, algo anacrónico e impensable desde nuestra perspectiva actual;

2. la segunda, vinculada a la ocupación de la mujer, sin duda la más amplia, se centra en el estudio de las matronas romanas en su doble

31 Entre otros trabajos destacan: CANTARELLA, E., "Potere femminile, diritto e stato tra mito e antropologia", Quaderni di Storia 14 (1988) 107-120; y HuMPHREYS, S.C., The Family, Women and Death: Comparative Studies, Londres 1983.

32 Por ejemplo BaLdson, J.P., Roman Women: their History and Habits, Nueva York 1983; CANTARElla, E., L'ambiguo malanno: condizioni e imagine della donna nell'antichità greca $e$ romana, Roma 1985, y «La vita delle donne», en Storia di Roma, vol. 4, Turín 1989, págs. $557-$ 608; y Pomeroy, S.B., Diosas, rameras, esposas y esclavas, Nueva York 1975, y Women's History and Ancient History, Carolina 1991.

33 Entre otros Dixon, S., The Roman Mother, Londres-Sidney 1988; GourEvITCH, D., Le mal d'étre femme, París 1984; HALLET, J., Fathers dn Daughters in Roman Society: Women and the Elite Family, Princeton 1984; LEFKOWITZ, M.R., Heroins and Histerics, Duckworth 1981; RUSSELL, L.M. (ed.), Feminist Interpretation of the Bible, Oxford 1985.

34 Para más detalles FOLEY, W., Reflexion of Women in Antiquity, Londres 1981; La dona en la Antiguitat, Barcelona 1987; La mujer en el mundo antiguo, Madrid 1986; Primer Congreso Peninsular de Historia Antigua, Santiago de Compostela 1986; Sullivan, C., Women in the Ancient World. The Arethusa Papers, Nueva York 1984. 
papel de procreadoras y mantenedoras del hogar, aunque, de acuerdo con la historiografía actual, la participación de la mujer esta atestiguada en todas las profesiones ${ }^{35}$, al menos las pertenecientes a clases poco acomodadas; $y$

3. y la tercera, conectada con la discriminación social y política de las mujeres en la época romana, sin distinción de rango o clase social, como consecuencia de la estructura patriarcal por un lado y de la concepción histórica del poder, en términos exclusivamente políticos, por otro.

En nuestros días la historiografía actual parece decantarse por dos caminos:

a) el de las síntesis bibliográficas y los avances ante la necesidad de recapitular no sólo debido a la abundancia, sino también a la dispersión de la investigación ${ }^{36}$; y

b) el buscar de dónde provienen los modelos que en la actualidad nos resultan tan familiares, tratando de desvelar la importancia del contexto histórico en su formación ${ }^{37}$.

\section{N.2. La problemática de las fuentes}

Mucho se ha discutido sobre los interrogantes que suscitan las fuentes de información con las que trabaja la historia antigua. ¿Cómo se puede hablar de las mujeres romanas si no existen testimonios directos de ellas? Un argumento similar se podría utilizar en el caso de los esclavos $y$, sin embargo, mucho se ha investigado y se ha escrito en torno a ellos.

No fallan las fuentes documentales sino las perspectivas históricas y cómo se las interroga. Para hacer progresar a la historia de las mujeres

35 Un exponente en LE GALL, J., "Metiers des femmes au Corpus Inscriptionum Latinarum», REL 47 bis (1969) 123ss.

उ6 Ver, por ejemplo, ARRIGoNI, C., "Tra ie donne dell'Antichità. Considerazioni e ricognizioni», en Studi sulla donna nel mondo antico, Ugolione, R. (ed.), Turín 1987; CuLHAN, P., "Ten Years after Pomeroy: Studies of the Image and Reality of Women in Antiquity", Helios N.S. 13 (1987) 9-30; Rabinowitz, N.S. - Richlin, A., Feminist Theory and the Classics, Nueva York 1993; TEJA R., "La mujer en el mundo antiguo. Síntesis histórica y balance de la investigación reciente", Actas $V$ Jornadas de Investigación Histórica Interdisciplinar, Madrid 1985, págs. 5-28.

37 SChmitPANTEL, P., "La historia de las mujeres en la historia antigua, hoy", en La historia de las mujeres, Dusy, G. y Perrot, M. (eds.), Madrid 1991, vol.1, págs. 538-547. 
romanas Cándida Martínez y Gonzalo Bravo proponen una serie de actividades $^{38}$ :

- releer las fuentes históricas tradicionales y, junto a ello, explotar nuevas fuentes de información (literarias, epigráficas, numismáticas, arqueológicas, estatuarias, pictóricas....);

- retomar viejos debates como el de la posible existencia de un matriarcado en las sociedades mediterráneas pre-históricas o históricas lo el de la acreditación de una sociedad matrilineal en el seno de ciertas poblaciones, como las castreñas por ejemplo); y

- romper la dicotomía de la historiografía del siglo XIX tratando de definir, en cada sociedad concreta, los roles sociales de hombres y mujeres y el tipo de relación mantenida, o bien discutir el concepto público/privado....

\section{IV.3. La historiografía moderna en España sobre la mujer romana}

La historiografía actual en España acerca de la mujer en la Antigüedad cuyos antecedentes han sido desarrollados con cierta profusión en el apartado segundo de este trabajo- se caracterizó en un primer momento por:

a) su gran contenido ideológico, debido a la influencia de la segunda oleda feminista de los años sesenta, y su marcado interés reivindicativo: romper la invisibilidad de las mujeres y encontrar en la Antigüedad movimientos de liberación similares a los actuales; y

b) la gran producción de trabajos referidos a la civilización griega, debido tal vez a la formación de gran parte de las investigadoras y a lo atractivo de las fuentes (en la actualidad Ana Iriarte es la figura más destacada en este ámbito).

Tras su incorporación a la historia de género y a partir de los ochenta nos encontramos con una serie de trabajos que analizan a la mujer romana en su perspectiva histórica ${ }^{39}$, visión muy discutida; o bien como sujeto produc-

\footnotetext{
38 BRAVO, G., «La mujer romana y la historiografía moderna: cuestiones metodológicas y nuevas perspectivas de estudio", La mujer en el mundo antiguo, Madrid 1986, págs. 54ss.; y MARTinez C., "Reflexiones sobre la historia de la mujer en el mundo antiguo», Actas del / Congreso Peninsular de Historia Antigua, Santiago 1986, vol. 1, págs. 205ss., y «Las mujeres en el mundo antiguo. Una nueva perspectiva para reinterpretar las sociedades antiguas", La mujer en el mundo antiguo, págs. 35ss.

39 Como ejemplo remitimos, entre otros, a los trabajos de DEL CASTILLO, A., La emancipación de la mujer romana en el siglo / d.C., Granada 1976, y «El sistema legislativo como elemento fundamental para el desarrollo femenino en el mundo romano", La mujer en el mundo antiguo, Madrid 1986, págs.
} 
tivo dentro del marco económico de la sociedad ${ }^{40}$, y finalmente desde una perspectiva relacionada con la discriminación social y política de la mujer en el seno de una sociedad patriarcal y de una concepción del poder en términos estrictamente políticos ${ }^{41}$.

La Universidad de Granada, centro promotor, productor y canalizador de gran parte de estas investigaciones, no ha de ser el único que soporte esta pesada responsabilidad histórica. Los Seminarios, Congresos, Jornadas... han de tener continuidad y proyección espacio-temporal.

Hay un largo y esperanzador camino por delante, al que deben sumarse tanto mujeres como hombres y que debe implicar a otros muchos distritos universitarios de la geografía española, a otros niveles educativos ${ }^{42}$ y a otros ámbitos, que no sean los estrictamente académicos.

\section{CONCLUSIONES}

Si hoy en día el papel de la mujer todavía se sigue cuestionando en alguna de las esferas de la sociedad, en lo referente a la investigación en

183-193; DeL HoYo, J., "La mujer hispanorromana de época imperial. Revisión de su papel», $V$ Jornadas de Investigación Interdisciplinaria, Madrid 1986, págs. 237-243; GALLEGO, M. ${ }^{2}$ H., "La consideración en torno a la mujer y su proyección en la sociedad de Hispania antigua», HAnt 16 (1992) 345-362; MONTERO, M., «La mujer en Roma», V Jornadas de Investigación Interdisciplinaria, págs. $195-204$.

40 Por ejemplo Bravo, G. "La mujer en la economía de la Hispania romana". Historia de las mujeres. La Antigüedad, Madrid 1991, págs. 579-585; DEL CASTILLO, A., «El papel económico de las mujeres en el Alto Imperio romano», RIS 9-10 (1974) 59-76; GALLEGo, M. ${ }^{\circledR} \mathrm{H}$., "La mujer hispanorromana y la actividad socioeconómica: las protesiones", Minerva 7 (1993) 111-127; y MARTinEZ, C., «Influencia social de las mujeres en las ciudades de la Hispania meridional», La mujer en el mundo mediterráneo antiguo, Granada 1990, págs. 230ss.

${ }^{41}$ Para más detalles ver, entre otros, Amorós, $C$., "Origen de la familia, origen de un malentendido", en Hacia una crítica de la razón patriarcal, Barcelona 1985; CASADO, M.J., La tutela de la mujer en Roma, Valladolid 1972; Del CASTILlo, A., "Apuntes sobre la situación de la mujer en la Roma imperial", Latomus 38 (1977) 171-187; GARcía GARRIDO, M., "lus uxorium», El régimen patrimonial de la mujer casade en el derecho romano, Roma-Madrid 1958, y El patrimonio de la mujer casada en el derecho civil, l: La tradición romanistica, Barcelona 1982; FERNáNDEz BAQUERO, M.E., "La mujer romana ante el divorcio", La mujer en el mundo mediterráneo antiguo, págs. 121135; GALLEGO, M. ${ }^{a}$ H., "Realidades onomásticas y sociales de la mujer hispanorromana palentina", Actas del III Congreso de Historia de Palencia, Palencia 1995, págs. 641-653; LoPEZ, A., "Escritoras latinas", Estudios de filología latina en honor de la Profa C. Villanueva Rico, Granada 1980 , págs. 45-69; RESINA SOLA, P., «La condición jurídica de la mujer en Roma», La mujer en el mundo mediterráneo antiguo, págs. 97-119; Rodriguez-Adrados, J.V., "Sistema onomástico de la mujer en el mundo romano", La mujer en el mundo mediterráneo antiguo, págs. 205-215.

42 Ver, por ejemplo, la propuesta de GALLEGO, M. ${ }^{a}$ H., "Un eje transversal: la mujer en la Antigüedad greco-romana", Historia Antigua en la Enseñanza. Didáctica de las Ciencias Sociales: Geografía e Historia, Barcelona 1995, págs. 39-54 
época clásica ha sido, es y continuará siendo objeto de seminarios, congresos, coloquios, jornadas y obras de divulgación, como los ya mencionados en las páginas anteriores.

Desde que el movimiento de mujeres, a partir de los años setenta, diera un impulso definitivo a la llamada «historia de las mujeres» al denunciar que las corrientes historiográficas de los últimos siglos presentaban como denominador común una visión parcial de la Historia -al excluir de ella la experiencia femenina- el camino es imparable.

El espíritu revanchista de los primeros tiempos, impregnado de una fuerte carga ideológica, unido a la gran variedad de métodos utilizados, dieron como resultado una ingente cantidad de publicaciones, que parecían querer demostrar la existencia de las mujeres, que sus cualidades eran más excelsas que las de los hombres y que, si habían guardado silencio, había sido debido a la opresión ejercida por el patriarcado imperante. $Y$ todo ello desde una perspectiva actual.

A mediados de los ochenta, una vez serenados los ánimos, surge un enfoque metodológico nuevo, la «historia de género», que, liberado de la pesada carga ideológica y aceptado y respetado - aunque con reticencias- en los ámbitos universitarios, ha supuesto una tabla de salvación para el futuro inmediato de los estudios de la mujer.

A través del nuevo análisis -la construcción social de los roles masculino y femenino - los temas de estudio han dado un giro y se han ampliado enormemente, al tiempo que se utilizan nuevas fuentes o se reinterpretan las que ya se consideran como clásicas.

En lo que concierne a la Historia Antigua en general, y a la mujer romana en particular, la producción de trabajos ha sido inicialmente inferior si la comparamos con otras etapas de la Historia. En la actualidad, y sin abandonar estudios de detalle ni la elaboración de síntesis que permitan conceder a las mujeres una identidad en el marco de la historia del mundo antiguo, los nuevos trabajos ya no presentan la imagen clásica de la mujer romana como matrona y/o ramera.

Estos nuevos estudios contextualizan la figura de la mujer entablando una relación, no de opresión sino de recíproco beneficio ${ }^{43}$; una mujer como elemento básico de las relaciones productivas en una sociedad eminentemente agrícola como la romana; participando en actividades públicas 
a través de las prácticas religiosas; y que mantiene una actitud de rebelión frente a la legislación e ideología oficiales, por ejemplo a través de las prácticas abortivas ${ }^{44}$.

En definitiva: las nuevas líneas de investigación deben huir de elaborar largos listados en los que se contrapongan los rasgos masculinos a las tareas, defectos o virtudes que se atribuían a las mujeres; deben dejar igualmente de interrogar al pasado desde la problemática moderna; deben de rechazar ser «capítulos» aparte en los manuales ortodoxos...

Las nuevas investigaciones tratan de colocar a las mujeres en el corazón de los procesos sociales, económicos, políticos y culturales. El reto que se nos plantea consiste, pues, en reescribir la historia pasada y empezar a escribir la historia presente desde la visión más globalizadora: la que integra la experiencia colectiva de toda la humanidad sin exclusión de clase, sexo, religión, género...

\section{BIBLIOGRAFIA}

Aguado, A.M. (y otros): Textos para la historia de las mujeres en España, Madrid 1994.

Bock, G.: «La historia de las mujeres y la historia del género: aspectos de un debate internacional», Historia Social 9 (1991) 55-57.

BrAIDOTTI, R.: «Teorías de los estudios sobre la mujer: algunas experiencias contemporáneas en Europa", Historia y fuenteoral 6 (1991) 3-16.

Bravo, G.: "La mujer romana y la historiografía moderna: cuestiones metodológicas y nuevas perspectivas de estudio", La mujer en el mundo antiguo, Madrid 1986, págs. 54-73.

Cantarella, E.: Pasado próximo. Mujeres romanas de Tácita a Sulpicia, Madrid 1997.

Duby, G. y PERROT, M.: La Historia de las mujeres, Madrid 1991, vol.1 (Introducción).

FARGE, A., "La historia de las mujeres. Cultura y poder de las mujeres: ensayo de historiografía", Historia Social 9 (1991) 79-101.

GALLEGo, M. a H.: «La consideración en torno a la mujer y su proyección en la sociedad de Hispania Antigua", HAnt 16 (1992) 345-362.

Gallego, M. ${ }^{a}$ H.: «La mujer hispanorromana y la actividad socioeconómica: las profesiones», Minerva 7 (1993) 111-127.

GaLLEGO, M." H.: “Un eje transversal: la mujer en la Antigüedad greco-romana», en Historia Antigua en la Enseñanza. Didáctica de las Ciencias Sociales: Geografia e Historia, Barcelona 1995, págs. 39-54

GALLEGo, M. ${ }^{\mathrm{a}} \mathrm{H} .:$ «Realidades onomásticas y sociales de la mujer hispanorromana palentina», Actas del III Congreso de Historia de Palencia, Palencia 1995, págs. 641-653.

GOODWATER, L.: Women in Antiquity: An annotated Bibliography, Nueva York 1975.

Martínez, C.: "Reflexiones sobre la historia de la mujer en el Mundo Antiguo", Actas del I Congreso Peninsular de Historia Antigua, Santiago de Compostela 1988, págs. 205-217.

MARTINEZ, C.: "Las mujeres en el mundo antiguo. Una nueva perspectiva para reinterpretar las sociedades antiguas", en La mujer en el mundo antiguo, Madrid 1986, págs. 35-54.

D. MiRON: «Las mujeres en la Antigüedad I», Feminae. Cuadernos Bibliográficos, Granada 1992.

44 Varios pasajes recopilados en AGUADO, A.M. y otros, Textos para la historia de las mujeres en España, Madrid 1994. 
NASH, M.: «Nuevas dimensiones en la historia de la mujer», Presencia y protagonismo. Aspectos de la historia de la mujer, Barcelona 1984, págs. 9-51.

NASH, M.: "Dos décadas de Historia de las mujeres en España: una reconsideración», Historia Social 9 (1991) 137-161.

OFFEN, K.: "Definir el feminismo: un análisis comparativo", Historia Social 9 (1991) 103-135.

Pomeroy, S.B.: Diosas, rameras, esposas y esclavas. La mujer en la Antigüedad clásica, Madrid 1987.

RAmOS, C.: «El concepto de género y su utilidad para el análisis histórico", La Aljaba segunda época 2 (1997) 13-32.

Rivera, M., Nombrar el mundo en femenino. Pensamiento de las mujeres y teoría feminista, Barcelona 1994.

Scotr, J.W., «El género: una categoría útil para el análisis histórico», en Historia y género. Las mujeres en la Europa moderna y contemporánea, AMELANG, J.S. y NASH, M. (eds.), Valencia 1990, págs. 23-56.

SchmitT, P., "La historia de las mujeres en la historia antigua, hoy", en La Historia de las mujeres, Duby, G. y Perrot, M., Madrid 1991, vol.1, págs. 537-547. 